\title{
Some Evolutionary Economics of Family Partnerships
}

\author{
Theodore C. Bergstrom ${ }^{1}$
}

\section{Food and Fire-An Arboreal Allegory}

Alice and Bob live in the forest. To sustain themselves, they collect fruits and berries and snare an occasional animal. The nights get cold, but Alice is a skillful fire-builder. Bob has never mastered this art. His fires fizzle and he never seems to collect the right kind of wood.

Alice divides her time between collecting food and gathering wood. She does this in such a way that her marginal benefit from time spent collecting food is the same as that from gathering wood. Bob does not attempt to build fires. He spends all of his time gathering food, and every night slinks up and huddles beside Alice's fire. Bob appreciates the fire's warmth, but wishes it were larger.

Bob has learned to leave morsels of food by the fire for Alice. Warmth and food are both "normal goods" for Alice. The extra food that Bob leaves induces her to increase her total food consumption, but not by the total amount that Bob leaves for her. She uses some of the time saved by Bob's gifts to gather more firewood.

\subsection{Equilibrium with Unilateral Gifts-An Example}

Alice's utility function is $U\left(c_{A}, y\right)=c_{A} y$ where $c_{A}$ is the amount of food that she eats and $y$ is the amount of wood on the fire. She has $T$ hours to allocate between collecting food and wood. In an hour, she can collect either one unit of wood or $\pi_{A}$ units of food. If Bob leaves $g$ units of food by the fire, she maximizes her utility by choosing

$$
y=\frac{1}{2}\left(T+\frac{g}{\pi_{A}}\right) \text { and } c_{A}=\frac{1}{2}\left(\pi_{A} T+g\right)
$$

Bob's utility function is $U\left(c_{B}, y\right)=c_{B} y$ where $c_{B}$ is his food consumption and $y$ is the amount of wood on Alice's fire. Bob is useless at collecting wood, but he is able to gather $\pi_{B}$ units of food per hour for $T$ hours. If $3 \pi_{A} \geq \pi_{B} \geq \pi_{A}$, then Bob maximizes his utility by selecting

$$
y=\frac{T}{4}\left(\frac{\pi_{A}+\pi_{B}}{\pi_{A}}\right) \text { and } c_{B}=\frac{T}{2}\left(\pi_{A}+\pi_{B}\right) .
$$

\footnotetext{
${ }^{1}$ Aaron and Cherie Raznick Professor of Economics, University of California, Santa Barbara.
} 
He achieves this outcome by giving $g=\left(\pi_{B}-\pi_{A}\right) T / 2$ units of food to Alice. In this case, Alice spends the fraction $\left(3 \pi_{A}-\pi_{B}\right) / 4$ of her time gathering food and the remainder of her time collecting wood.

If $\pi_{B} \leq \pi_{A}$, then in equilibrium, Bob gives Alice no food and Alice divides her time equally between collecting food and wood gathering. She collects $c_{A}=$ $\pi_{A} T / 2$ units of food and $y=T / 2$ units of wood.

\subsection{Pareto efficiency and conditional payments}

Although Bob and Alice both benefit when Bob leaves food for Alice, unilateral gifts do not achieve full Pareto efficiency. In equilibrium with unilateral gifts, Alice's marginal rate of substitution between fire and food equals the marginal $\operatorname{cost} \pi_{A}$ of wood relative to food. But the fire is a public good for Alice and Bob. If Alice is not spending all of her time gathering wood, and if the sum of Alice's and Bob's marginal rates of substitution exceeds $\pi_{A}$, then both persons can be made better off if Alice gathers more wood. At a Pareto optimal allocation:

$$
y=T\left(\frac{\pi_{A}+\pi_{B}}{2 \pi_{A}}\right) \text { if } \pi_{B} \leq \pi_{A} \text { and } y=T \text { if } \pi_{B} \geq \pi_{A} .
$$

Any change that is a Pareto improvement on unilateral equilibrium requires Bob to transfer more food to Alice and Alice to supply a larger fire. If Bob could observe the way that Alice spends her time, the two parties could support Pareto optimal outcome by means of payments from Bob to Alice for gathering firewood. But this may not be possible if Bob is not be able to monitor Alice's activities and if there is randomness in the relation of the size of fire to Alice's effort. In a Pareto optimal allocation, Alice's marginal rate of substitution between fire and food is less than the marginal cost of fire and therefore Alice could increase her utility by clandestinely substituting a bit of food collection for wood gathering.

\subsection{Common Interests}

Suppose that the only thing that Alice and Bob really care about is the size of the fire. Both consume food, but they do so merely to give themselves the strength to make greater net contributions to their ultimate goal, a large fire. Then Alice and Bob both have dominant strategies. Each maximizes utility by choosing consumption to maximize his or her net output. There are no problems of incentives or moral hazard and there is no need for monitoring. Since their 
interests coincide, Alice wants to allocate her efforts and resources in exactly the same way that Bob would choose for her. Likewise Bob wants to allocate his efforts in exactly the same way that Alice would have chosen for him. We also see that in this case, any technical change that increases productivity in food collection will lead them to increase the size of the fire, regardless of the effect on the relative costs of food and fire.

\section{How are children like fire?}

As you may have guessed, the allegory of Alice, Bob, and the fire is intended to represent the choices confronted by a female and a male whose offspring share their genes. Evolutionary theory predicts selection for genes that produce behavior that tends on average, to maximize the number of their surviving descendants. This theory suggests that evolution would select for individuals who act as if personal consumption is not an end in itself, but rather an instrument for reproductive success. Such individuals would pursue goods and leisure insofar as they result in increased health, strength, and longevity, which in turn allow them to produce more thriving children and grandchildren.

Couples who bond in lifelong monogamous relationships share a fundamental common interest. Since they share the same line of descendants, actions that maximize the reproductive success of one must also maximize that of the other. Each is an agent of the reproductive success of the other, so natural selection would favor the emergence of mutual concern between spouses. If this common interest were complete, the evolved nature of humans could potentially support the biblical injunction, "Love thy neighbor as thyself."

As realism is added, discordant elements intrude on this idyll. Even in a monogamous, lifelong partnership, the genetic interests of husband and wife do not coincide perfectly. "The inlaw problem" is a source of dissonance common in popular mythology. According to the biological theory of kin-selection, [13] [4] natural selection favors individuals who value the reproductive success of their siblings at half of their own. If one sibling is prosperous and the other has fallen on hard times, then by giving resources to his unfortunate sibling, a prosperous individual may benefit the sibling's reproductive success by more than twice the cost to his own. The prosperous sibling then has a genetic interest in making a transfer. Since the relatives of one spouse are not closely related to the other, kin-selection theory predicts that monogamous couples will disagree about when 
to help needy inlaws.

Through most of our evolutionary history, death rates of men and women in their prime reproductive years were high. There was a significant chance that one partner would die and the surviving partner would remarry and have children with another partner. A man's reproductive interest would favor shorter birth intervals than his wife's, since if she dies in childbirth, he may be able to remarry and continue to reproduce.

Anthropologists find adultery to be common in a wide variety of human societies. Males who are uncertain of the paternity of existing children have a smaller genetic stake in the quality of existing children and stand to gain more net fertility from an additional child than would their spouses. This conflict is especially strong when divorced persons remarry. Fortunately, human males are not as resolute in their genetic self-interest as male lions or chimpanzees who, when they encounter a nursing mother with whom they have not et mated, will kill the infant in order to bring the mother into oestrus. Some of these inclinations seem to persist in our species. Evolutionary psychologists, Martin Daly and Margo Wilson's [9] show that child abuse by stepfathers is far more frequent than by biological fathers or by mothers. Studies by Heather Antecol and Kelly Bedard and by William Comanor and Llad Philips [3][8] find that children raised by stepfathers are much more likely than children raised by two biological parents to engage in anti-social activity and to experience trouble with the law.

\section{The Demographic Transition}

The demographic transition that swept through Western Europe in the late 19th and early 20th century, and followed economic development in much of the world, presents a stiff challenge both to standard economic theories and to evolutionary theories of reproductive behavior. In Western Europe, starting in about 1870, real wages began to rise at a rate of about 2 per cent per year. Over the same period, net reproduction rates fell from an average of three surviving children per woman in 1860 to slightly fewer than two in the modern era [6]. Gross reproduction rates fell even more rapidly, as infant mortality declined sharply. In the latter half of the twentieth century, a similar pattern of rising wages and falling birth rates occurred in developing countries of Asia and Latin America. Cross country comparisons in modern times show a negative relation 
between per capita income and net fertility.

Evolutionary biologists find it puzzling a species would reproduce less rapidly when individuals have access to more material resources. [1] They would expect natural selection to favor animals that increase their fertility when resources are more abundant over those who pursue the opposite strategy. Thus there are strong evolutionary reasons to expect children to be "normal goods."

An economist's reflexive response is that if income effects don't explain the data, substitution effects can do the trick. As real incomes rose, so did real wages, and hence the cost of child-rearing - a relatively labor-intensive activity. If the negative price effect overwhelmed the positive income effect of real wages, fertility could decrease. In our example with Alice and Bob, if both became more productive at collecting food while Alice's wood-gathering productivity did not change, then, as seen from Equations 2 and 3, the equilibrium size of the fire would not change. This invariance follows from our assumptions that utility is Cobb-Douglas and that the relative cost of fire rises at the same rate as productivity in food collection.

In general, for wages and fertility to move in opposite directions it must be that the cost of children rises more rapidly than the ratio of the absolute value of price elasticity to the income elasticity. This is a strong assumption, and nobody seems to have collected direct evidence that it is satisfied. Even stronger assumptions would be needed to rationalize the cross sectional data. Prior to the industrial revolution, it appears that fertility was a normal good. Data collected from wills of male testators in preindustrial England [7] and from eighteenth and nineteenth century church records and tax records in Germany, [22], Sweden [17], and Norway [20] all find reproductive success to be positively related to wealth and occupational status. In contrast, in modern economies there seems to be little or no correlation between income and wealth. [10] [15].

We are left with challenging questions. Why was there positive correlation between wealth and fertility before the demographic transition, but not after? If children are normal goods and if rich and poor face the same prices for inputs to raising children, why is fertility not positively correlated with income? Of course the costs of child rearing are not entirely constant across incomes. Childrearing costs are likely to increase with parents' wages, since parents must use at least some of their own time in child care. But household help, child care workers, and school teachers can all be hired at market wages.

Björn Gustafsson and Urban Kjulin [12] use Swedish time diaries and household accounts to estimate that "active child care" amounts to less than one- 
fourth of the cost of child-rearing for children of age 0-7 years. "Other housework" constitutes about one half of the costs, and housing and goods and services account for the remainder. If the wealthy choose to provide all of the "active child care" but purchase the remaining inputs for child care at market prices, then in cross section, wage differences would be accompanied by differences in child care costs that are about one fourth as large. In order to explain the invariance of number of children to wealth, we would need the price elasticity of demand for children to be four times as large as the income elasticity.

Gary Becker [2] proposed a potentially more powerful source of price effects. Technical change increased the schedule of returns to human capital. As a result, the optimal level of human capital investment per child, and hence the cost of producing an optimally educated child, has increased. This explanation seems to require that rates of return to human capital increased over time, despite a large increase in its supply. Clark [6] maintains that "in England and a variety of other pre-industrial countries, the rewards to human capital were higher than in the modern economy." According to Clark, the ratio of wages of craftsmen to those of laborers fell steadily from the eighteenth century to the present. If this is the case, then increases in the supply of human capital must somehow have been the result of a shift in the demand curve for human capital, rather than a movement along an unchanged demand curve.

\subsection{Power Shifts?}

There is reason to believe that humans evolved under circumstances of less than complete monogamy and hence there are systematic conflicts of genetic interests between marriage partners. In deciding whether to have another child, a woman must weigh the expected long term success of this child against the cost in diluted resources for her previously born children. While the mother has an equally large genetic stake in her previously born children as in a potential newborn, the interests of her mate in the older children must be discounted by the probability that they are not his. Furthermore, although her reproductive career would end if she should die in childbirth, he may be able to remarry and continue to reproduce.

A large and growing literature of empirical consumer demand studies reject the hypothesis that household consumption behavior can be explained by the decisions of a single rational agent acting for the entire family. (See for example, Martin Browning et al, [5] and Lundberg et al [18].) These studies find that 
pattern of consumer expenditures in households is significantly influenced by the relative bargaining power of the partners, as measured by their non-labor incomes. Duncan Thomas [21] found that in Brazilian families, unearned income of the mother has a much stronger effect on measures of child health than that of the father. John Hoddinott and L. Haddad [14] found similar results for the Cote d'Ivoire. Cheryl Doss [11] found that in Ghana the share of assets owned by the wife had positive effect on the share of household expenditures going to food and education and negative effects on the share going to alcohol and tobacco.

Jerome Barkow, an anthropologist, and Nancy Burley, a biologist [1] proposed that because of genetic conflict of interest between mates, evolution could have shaped preferences so that "human females would fail to bear the optimal number of children in the absence of pressure of mates and kin." Birth intervals would reflect the outcome of a tug-of-war between mates, where the difference in the evolved target birth intervals of the two sexes exaggerate the difference in their true genetic interests. Thus men would desire more children and women fewer children than their own genetic interest dictates. Differences in birth rates across time and between cultures would occur as one side or the other gains increased leverage in this tug-of-war. A partial explanation of the modern emergence of high incomes and of birth rates slightly below replacement levels could be that in modernized economies, women have increased influence in household decisions and, together with improved contraceptive technology, have gained greater control of their own fertility. Clark [6] proposes a similar view. He points to the historical coincidence of the rise of literacy in women and the onset of the demographic transition. He takes this as evidence of the rising status of women with a resulting shift in household decisions toward family sizes preferred by women.

Empirical studies of differences between the number of children preferred by men and the number preferred by their wives are surprisingly rare. Using data from the Malaysian Family Life survey, Imrul Rasul [19] finds that in interviews, Malaysian husbands say they want more children than their wives. Rasul finds that when measurable household bargaining power favors the wife, a couple tends to have fewer children. In a survey of Brazilian households, Emily Klawon and Jill Tiefenthaler [16] find that as the ratio of the wife's non-labor income to the husbands increases, couples tend to have fewer children. Like Rasul, they interpret this result as an indication that as women gain bargaining power in the household they use this influence to achieve lower fertility than 
their husbands would prefer.

\section{Conclusion}

If fertility were in the domain of rational choice, evolutionary theory would predict that the human utility function would focus on expected long term fertility, a prediction that seems to be soundly rejected by the demographic transition. Kaplan and his coauthors [15] propose that in humans, while cognitive processes have evolved to manage decisions about parental investment, fertility through most of human history has been regulated by physiological processes such as nutrition and breast-feeding. In the modern era, returns to parental investment per child do not diminish until extremely high levels are reached. At the same time, people have begun to exercise cognitive control of reproduction through contraception.

No simple economic or biological theory seems adequate to explain the historical relation between wages and fertility. Quite likely, the reason is that multiple causes interact in a more complex way than we have imagined. The period of the demographic transition has seen many fundamental changes whose influences are likely to be intertwined. Mortality rates have declined drastically, for children and for adults. Living and working conditions have changed drastically with the movement from the farms to the city. The principle source of family wealth has changed from land ownership to physical and human capital. Effective contraceptive devices have become widely available and socially approved. Some of the observed paradoxical behavior may result from the fact that fertility decisions are not the rational choice of a single agent, but a joint decision of two individuals whose interests are partly in conflict. 


\section{References}

[1] Jerome H. Barkow and Nancy Burley. Human fertility, evolutionary biology, and the demographic transition. Ethology and Sociobiology, 1(3):163-180, 1980.

[2] Gary Becker. Fertility and the economy. Population Economics, 5:185-202, 1992.

[3] Kelly Bedard and Heather Antecol. Does single parenthood increase the probability of teenage promiscuity, substance use and crime? Journal of Population Economics, to appear, 2007.

[4] Theodore Bergstrom. On the evolution of altruistic ethical rules for siblings. American Economic Review, 85(1):58-81, March 1995.

[5] Martin Browning, Francois Bourguignon, Pierre-André Chiappori, and Valérie Lechene. Incomes and outcomes: A structural model of intrahousehold allocation. Journal of Political Economy, 1994.

[6] Gregory Clark. Human capital, fertility, and the industrial revolution. Journal of the European Economic Association, 3:505-515, April-May 2005.

[7] Gregory Clark and Gillian Hamilton. Survival of the richest: The Malthusian mechanism in pre-industrial england. The Journal of Economic History, 66(3):1-30, September 2006.

[8] William Comanor and Llad Phillips. The impact of income and family structure on delinquency. Journal of Applied Economics, 5(2):209-232, 2002.

[9] Martin Daly and Margo Wilson. Homicide. Aldine de Gruyter, New York, 1988.

[10] Nicola Dickmann. Fertility and family income on the move-an international comparison over 20 years. Working Paper 360, Maxwell School of citizenship and public affairs, Syracuse University, Syracuse, New York, October 2003.

[11] Cheryl Doss. The effects of intrahousehold property ownership on expenditure patterns in Ghana. Journal of African economies, 15(1):149-180, 2005. 
[12] Björn Gustafsson and Urban Kjulin. Time use in child care and housework and the total cost of children. Journal of Population Economics, 7(3):287306, September 1994.

[13] William D. Hamilton. The genetical evolution of social behavior, i and ii. Journal of Theoretical Biology, 7(1):1-52, July 1964.

[14] John Hoddinott and L. Haddad. Does female income share influence household expenditures: Evidence from the Cote d' Ivoire. Oxford Bulletin of Economics and Statistics, 57:77-96, 1995.

[15] Hillard S. Kaplan, Jane B. Lancaster, Johnson Sara E., and John A. Bock. Does observed fertility maximize fitness among New Mexico men? Human Nature, 6(4):325-360, 1995.

[16] Emily Klawon and Jill Tiefenthaler. Bargaining over family size: the determinants of fertility in Brazil. Population Research and Policy Review, 20:423-440, 2001.

[17] Bobbi S. Low and Alice Clarke. Resources and the life course: Patterns through the demographic transition. Ethology and Sociobiology, 13:463494, 1992 .

[18] Shelly Lundberg, Robert Pollak, and Terence Wales. Do husbands and wives pool their resources? Journal of Human Resources, 32(3):463-480, Summer 1997.

[19] Imran Rasul. Household bargaining over fertility. Technical report, University College of Lonedon, Dept of Economics, UCL, Gower Street, London WC1E, UK, November 2005.

[20] Evin Røskoft, Annalise Wara, and Viken Åslaug. Reproductive success in relation to resource-access and parental age in a small Norwegian farming parish during the period 1700-1900. Ethology and Sociobiology, 13:443-461, 1992.

[21] Duncan Thomas. Intra-household resource allocation an inferential approach. Journal of Human Resources, 25(4):635-664, 1990.

[22] Eckhard Voland and Robin Dunbar. Resource competition and reproduction, the relation between economic and parental strategies in the Krummhörn population. Human Nature, 6(1):33-49, 1995. 